\title{
TOWARDS DEVELOPING AN EARLY WARNING SYSTEM FOR CUCUMBER DISEASES FOR GREENHOUSE IN CHINA
}

\author{
Ming $\mathrm{Li}^{1,2}$, Chunjiang Zhao ${ }^{1, *}$, Daoliang $\mathrm{Li}^{2}$, Xinting Yang ${ }^{1}$, Chuanheng \\ Sun $^{1}$, Yan'an Wang ${ }^{3}$ \\ ${ }^{1}$ National Engineering Research Center for Information Technology in Agriculture, Key \\ Laboratory for Information Technologies in Agriculture, the Ministry of Agriculture, Beijing, \\ China, 100097 \\ ${ }^{2}$ College of Information and Electrical Engineering, China Agricultural University, Beijing, \\ China, 100083 \\ ${ }^{3}$ College of Life Science, Shandong Agricultural University, Taian, Shandong Province, China, \\ 271018 \\ * Corresponding author. Address: Room 320, Beijing Agricultural Science Mansion, Building \\ A, Banjing, Haidian district, Beijing, 100097, P. R. China, Tel: +86-10-51503411, Fax: \\ +86-10-51503750, Email: zhaocj@nercita.org.cn (Chunjiang Zhao)
}

Abstract: $\quad$ The integrated management of cucumber (Cucumis sativus L.) diseases play a key role in guaranteeing the high quality and security of cucumber production in greenhouse, moreover, the early warning of cucumber diseases is the chief precondition for IPM (Integrated Pest Management). This paper describes an attempt to develop an early warning system for cucumber diseases in greenhouse. By analysing plant disease epidemiology and early warning theory, the conceptual model of early warning on cucumber disease of greenhouse is developed. The data collection, data transfer system, database system, forecast system, warning system, and so on are integrated and an early warning system for cucumber diseases in greenhouse has been designed.

Keywords: cucumber (Cucumis sativus L.), greenhouse, disease, early warning system

Li, M., Zhao, C., Li, D., Yang, X., Sun, C. and Wang, Y., 2008, in IFIP International Federation for Information Processing, Volume 259; Computer and Computing Technologies in Agriculture, Vol. 2; Daoliang Li; (Boston: Springer), pp. 1375-1378. 


\section{INTRODUCTION}

Concerns about food safety, environmental quality and pesticide resistance have dictated the need not only for diagnosis and controlling the diseases, but also for forecasting them correctly and providing preventive measures for planters, namely providing an early warning. In order to develop a reliable and effective early warning system, it is necessary to understand related information concerning epidemiology of pathogens, greenhouse microclimate, cucumber growth and agronomic practices (Jeger, 2004).

The early warning theory has been originated from military affairs, and extended to economy, earth quake, flood, biological disaster early warning and so on. There have been many pest-warning system, such as for processing tomato (Gleason et al., 1995), pear blossom blast (Latorre et al., 2002) and cotton bollworm (Bai et al., 2002), but few studies of cucumber diseases early warning/forecast system in greenhouse have been conducted. Xu et al. (2003) developed a forecasting and management system of cucumber powdery mildew and downy mildew in plastic greenhouse tunnel, which is not based on real-time environmental information. A greenhouse intelligent ecohealth wardship system for tomato ( $\mathrm{Lu}$ et al., 2004) and ecosystem monitoring and the decision system for diseases and insect pest management of cucumber in non-heated greenhouse (Ju, 2006) are reported, but both need more support of accurate predictable warning models. The lack of such information represents a gap in our knowledge of disease warning systems, thus combining disease early warning model with greenhouse environment data logger, an early warning system for cucumber diseases in greenhouse has been designed.

\section{CONCEPTUAL MODEL OF EARLY WARNING}

According to plant epidemiology and early warning theory, the conceptual model of early warning on cucumber disease in greenhouse is designed, which includes five following steps. The first one is warning index confirmation. The early warning model predicts outbreak time and grade of diseases, which are also warning index. Outbreak time is the date when diseases become visible, which is calculated from the transplanting date. Coming to the grade of diseases, disease index (DI) is the integration of disease incidence and disease severity as an acceptable sign. The second one is warning indicators analysis. As to a specific disease, such as cucumber downy mildew or powdery mildew, there will be some domain factors for plant disease epidemic. Taking cucumber downy mildew for example, 
relative humidity $(\mathrm{RH})$, duration of leaf wetness and air temperature are main environmental factors for infection and epidemic. Then, warning source search is the third one. It will present the warning source, such as the times of irrigation is excessive, the greenhouse ventilation effect is poor or the daily temperature range is much and so on. Later one is warning in time. After warning source search, the warnings are issued through sound alarm and caution light. The caution light uses a key with 5 disease classes $(0,1,2$, 3 , 4; from none to severity) and defines green, blue, yellow, orange and red warning signal respectively. Then, the users can judge the warning based on integrated greenhouse circumstances and their experiences. The last one is warning obviation. During the process of warning obviation, the users can input the real-time information and acquire change of disease-warning, which is helpful for decision-making. If the warning management is over, the warning will be relieved by users.

\section{SYSTEM ARCHITECTURE}

The early warning system uses techniques of inference machine from artificial intelligence and expert systems to provide smarter support for the decision-maker, which include four parts mainly. The core of the system is model base. The development of models is embedded in an object-oriented approach that emphasizes the separation of models from data and promotes model and data integration and reuse (A.E. Rizzoli et al., 1998). So the model management system allows the user to find a model corresponding to historical data, to modify a selected model and to compose a new model, possibly assembled from existing ones. Then the forecast (inference) machine integrates the method of the mathematical model and rule-based model. The rule-based model is used for predicting the disease outbreak day and the mathematical model is employed for calculating the epidemic degree of disease in a few days later. Followed, the warning machine is started up. Warning machine in office is dependent on the main computer and work in ways of sound alarm and caution light, which consists of components for user login, data import, query and statistics, and system maintenance.

\section{CONCLUSION}

To avoid known barriers hindering the broader acceptance of early warning system, the development team identifies a prerequisite which has guided development and applications. In developing an early warning model, 
pathogen, agronomic, environmental and host factors should be taken into account (Shtienberg, 2000). An important aspect comprises the possible interactions among parameters, which sometimes may be complex. For example, the amount of fertilization may directly affect the response of the host plant to the pathogens, while excessive fertilization might result in excessive growth of the foliage, which, in turn, would affect the microclimatic conditions within the canopy. Consideration of all parameters, and their interactions, may enable the grower to adequately predict the likelihood of a disease outbreak. So integrated above knowledge and models, the early warning system for greenhouse cucumber diseases will be more practical.

\section{ACKNOWLEDGEMENTS}

It is an outcome of National Key Technology R\&D Program (No: 2006BAD10A08) and Huo Yingdong Young Teacher's Foundation (Contract No: 94032).

\section{REFERENCES}

Bai L.X., Sun Y.W., Jin Z.Q. The Development of the Early Warning to the Cotton Bollworm Calamity and Its Auxiliary Control Decision-making System (MLCYJJC-CDROM), Cotton Science, 2002, 14: 166-170 (in Chinese).

Gleason M.L., MacNab A.A., Pitblado R.E., et al. Disease-Warning System for Processing Tomatoes in Eastern North America: Are We There Yet? Plant Disease, 1995, 79: 113-121.

Jeger M.J. Analysis of disease progress as a basis for evaluating disease management practices. Annual Review of Phytopathology, 2004, 42: 61-82.

$\mathrm{Ju}$ R.H. Ecosystem monitoring and the decision system for diseases and insect pest management of cucumber in SES greenhouse. PhD thesis, China Agricultural University, Beijing, China (in Chinese), 2006.

Latorre B.A., Rioja M.E., Lillo C. The effect of temperature on infection and a warning system for pear blossom blast caused by Pseudomonas syringae pv. Syringae. Crop Protection, 2002, 21: 33-39.

Lu J. Research on Greenhouse Intelligent Ecohealth Wardship System (GH-Healthex) Base on Tomato. Masteral Dissertation, China Agricultural University, China, 2004 (in Chinese).

Rizzoli A.E., Davis J.R., Abel D.J. Model and data integration and re-use in environmental decision support systems. Decision Support Systems, 1998, 24: 127-144.

Shtienberg D. Modelling: the basis for rational disease management. Crop Protection, 2000, 19: 747-752.

$\mathrm{Xu}$ N. Forecasting and management system of cucumber powdery mildew and downy mildew in plastic greenhouse tunnel. Masteral Dissertation, Nanjing Agricultural University, China, 2003 (in Chinese). 